\title{
A primera sang: batalles nupcials en la Catalunya barroca. Els epitalamis al galant Alba de Francesc Fontanella*
}

\author{
A primera sang: nuptial battles of the Catalan Baroque. \\ The epithalamia to gallant Alba by Francesc Fontanella
}

\author{
AnNa Garcia Busquets \\ a.garcia.busquets@gmail.com \\ Universitat de Girona
}

\begin{abstract}
Resum: A l'antiga Grècia i Roma els epitalamis actuaven com a preludi eròtic de la nit nupcial. Claudià, a l'antiguitat tardana, va tractar el motiu del desflorament com a pugna amoris amb lasciu refinament. A partir del Quattrocento italià, l'Europa moderna va reprendre amb profusió aquesta tradició laudatòria d'erotisme estilitzat amb cants consagrats a la unió de les famílies il lustres. El poeta barroc Francesc Fontanella (16221682/83) va compondre quatre magnífics epitalamis dedicats a les noces d'un enigmàtic personatge: el 'galant Alba'. Diversos estudis han intentat, sense èxit, desvelar-ne la identitat. En aquestes composicions, Fontanella va emprar un llenguatge refinat i metafòric per descriure gradualment els estadis que porten a la unió carnal entesa com a lluita amorosa: els versos, rics en imatges florals i minerals, s'han de reconvertir al seu sentit concret a través d'una doble lectura. L'estudi inclou l'edició crítica dels textos i la contextualització del cicle dins del corpus epitalàmic europeu, així com una argumentació sobre la possible identitat dels protagonistes.
\end{abstract}

Paraules clau: literatura catalana moderna; poesia barroca; epitalami; Francesc Fontanella

Abstract: In ancient Greece and Rome, epithalamia acted as an erotic prelude to the wedding night. In Late Antiquity, Claudian explored the theme of deflowering as pugna amoris with lascivious refinement. As of 15th century Italian poets, modern Europe recommenced this laudatory tradition of stylised eroticism with songs devoted to the union of illustrious families. The Baroque poet Francesc Fontanella (1622-1682/3) composed four magnificent epithalamia dedicated to the wedding of an enigmatic character: 'gallant Alba', of whom several studies have tried, unsuccessfully, to reveal his identity. In these compositions, Fontanella employed refined, metaphorical language to gradually describe the stages of carnal union understood as a love battle: the verses, rich in floral and mineral imagery, must be transformed into their particular meaning through double reading. The study includes the critical edition of the texts and a contextualisation of the series within the European corpus of epithalamia, as well as an argument on the possible identity of the protagonists.

Keywords: Early modern Catalan literature; Baroque poetry; epithalamium; Francesc Fontanella

\footnotetext{
* Aquest treball s'insereix en les recerques del projecte FFI2015-70095-P del MINECO. Agraeixo les observacions que m’ha ofert Pep Valsalobre i, quant a l'edició dels textos, els comentaris d'Albert Rossich, Pep Valsalobre, Marc Sogues i Marta Castaño. Aquest estudi es va presentar en forma de comunicació a la LXII Anglo-Catalan Society Annual Conference, University of Leeds 11-13 November 2016
} 
Anna Garcia Busquets. A primera sang: batalles nupcials en la Catalunya barroca.Els epitalamis al galant Alba de Francesc Fontanella

L'epitalami és un subgènere poètic de tipus encomiàstic que es limita a la circumstància social concreta d'un casament. ${ }^{1} \mathrm{Al}$ llarg dels anys, els motius temàtics més tractats pels epitalamis han estat la defensa de la institució del matrimoni i de l'amor conjugal, la descripció de la cerimònia, l'elogi dels nuvis i de les seves virtuts, el desig de prosperitat per a la parella i l'exhortació -d'una manera més o menys evident a la procreació. Tot seguit examinarem sumàriament alguns exemples de la tradició a fi de contextualitzar el cicle del galant Alba de Francesc Fontanella.

\section{Antiguitat clàssica}

Tant a Grècia com a Roma, els epitalamis actuaven com a preludi eròtic de la nit de noces. ${ }^{2} \mathrm{~A}$ la lírica arcaica grega en consten tant de corals (Alcmà) com en versió monòdica (Safo), o d'inserits en la comèdia i tragèdia clàssiques. Del període hel lenístic ha pervingut l'idil li XVIII de Teòcrit, de caràcter mític. Reprodueixo un fragment de l'encomi de la núvia que ha fet fortuna, del qual tornarem a parlar més endavant. Hèlena brilla, fent ús del tópos de la bellesa contrastada, preeminent sobre les companyes:

Som, en total, quatre vegades seixanta donzelles, una munió de verges. I bé, cap de nosaltres no és perfecta del tot comparada amb Hèlena.

Quan l'alba apunta, oh nit venerable, mostra el seu rostre resplendent com, en finar l'hivern, la clara primavera: així mateix l'àurea Hèlena resplendeix entre totes nosaltres.

Unes altes messes són l'ornament del fèrtil camp; d'un jardí, el xiprer; d'un carro, una egua tessàlia: així mateix Hèlena, la de la pell rosada, és l'ornament de Lacedemònia (Epitalami d'Hèlena vv. 24-31, Alsina 1963: 99). ${ }^{3}$

A l'època romana la processó nupcial s'amenitzava amb els versos fescennins -uns cants populars de contingut satíric i burlesc expressat amb total llibertat- en els quals es va inspirar la producció llatina d'autor, entre la qual sobresurten els epitalamis de Catul, Estaci, Ausoni i Claudià. A la

1 Estrictament hauríem de distingir entre gamélios (cançons per al banquet), bimeneus (cants processionals per acompanyar els nuvis a casa), i epithalamios (discursos davant la cambra nupcial), encara que a la literatura i a la crítica predomina un sentit ampli del terme 'epitalami', entès simplement com a 'poema nupcial' (Martínez Sariego 2010: 262). Alguns estudiosos, a partir de la distinció establerta pel retòric Menandre de Laodicea (finals s. III dC), marquen la diferència entre 'epitalami' (composició de caràcter genèric sobre el tàlem, la família i el déu del matrimoni, pronunciat durant el casament) i 'discurs del llit nupcial' o kateunastikós lógos, centrat en la incitació a la unió (Tractat II, 399-412, García, M. / Gutiérrez, J. 1996). Ponce Cárdenas detalla les següents particularitats del subgènere kateunastikós lógos: incitació a la unió, brevetat de les composicions, tractament elegant de la matèria lasciva i formulació consiliària (2010: 204).

2 Sobre l'erotisme als epitalamis clàssics, veg. l'article de Serrano Cueto (2013) en què alguns dels textos són analitzats com a antecedents de la poesia nupcial llatina dels segles XV i XVI.

3 «De hecho, tan extraordinario es el brillo que desprende la bella Hélena que su parangón ha de hacerse no con seres humanos sino con aquellos agentes naturales que tienen en la luz su propiedad más preciada. (...) Y tampoco debió de serle desconocido al género las comparaciones de la novia con el mundo natural. (...) sucediéndose en paralelo tres haces de opuestos con el común motivo del extraordinario brillo como tertium comparationes: el primero ("Aurora / Noche") y el segundo ("primavera / invierno") serían conceptualmente los comparantes del tercero ("Hélena / compañeras")», afirma Montes Cala (1996: 46 i 48) en un interessant estudi que aprofundeix en la interpretació dels vv. 26-28 de l'idil li XVIII. 
Anna Garcia Busquets. A primera sang: batalles nupcials en la Catalunya barroca.Els epitalamis al galant Alba de Francesc Fontanella

composició LXI de Catul, dedicada a les noces del seu jove amic el patrici Mal li Torquat, hi ha una clara invitació als gaudia i a tenir descendència sense tardar:

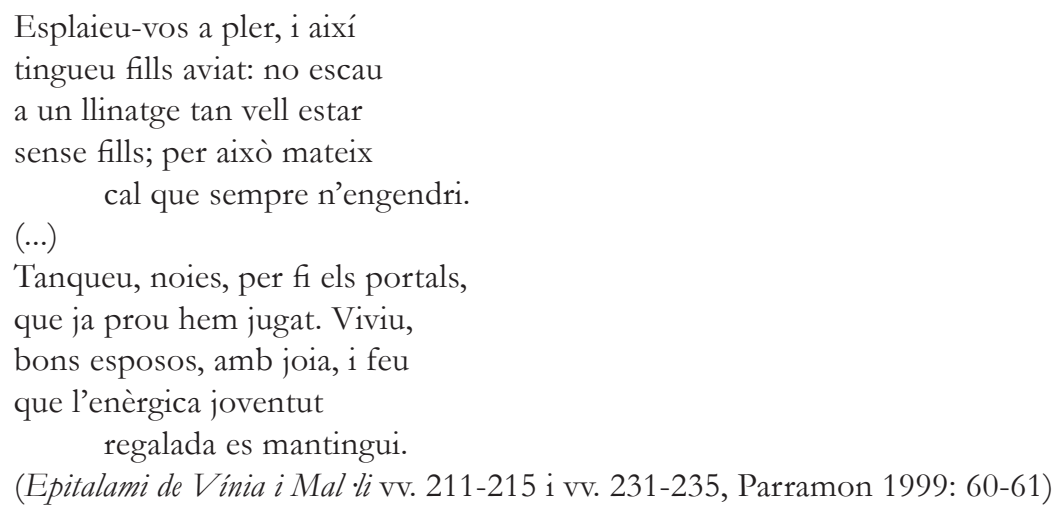

Estaci (Silves I 2) va ometre parlar directament dels plaers de la nit, però en el discurs de Venus a la núvia Violentil la va incloure una interessant defensa de la institució del matrimoni com a garant ordenat de la perpetuació de les espècies:
¿Quins pobles, quins cors no he sotmès a la torxa conjugal? Ocells, bestiar, cruels escamots de feres, res no m'ha desobeï; l'aire mateix, quan els núvols es fonen en pluja, el dissolc en una unió amb la terra. Així la cadena dels éssers i l'edat del món es renovellen (Silves I 2, vv. 184- 187, Colom / Dolç 1957: 63-64).

Estel la, el nuvi poeta, ha patit llargament esperant Violentil la: un amoret el va travessar de ple fa anys amb una pluja de sagetes, mentre ella només va ser tocada lleugerament. Uns versos de Fontanella que veurem més endavant recorden aquest passatge:

\begin{abstract}
$\mathrm{Tu}$, amb tot, meravellat, encara que tinguis al teu abast una nit tan plena de promeses, no t'atreveixes a passar del desig i tems la sort que et concedeix un déu propici. Deixa, oh poeta estimat, aquests sospirs, deixa'ls: ja és teva. Pots anar i venir amb pas franc per la porta oberta: ja no ho impedeix cap guardià ni la llei ni el pudor. Assacia't a la fi de l'estreta enyorada -ha vingut l'hora-i recorda't ensems de les dures nits passades (Silves I 2, vv. 31-37, Colom / Dolç 1957: 57.
\end{abstract}

A més de Catul i Estaci, un altre referent clàssic és Ausoni i el seu Centó Nupcial, que no és pròpiament un epitalami, sinó un joc literari fictici basat en la tècnica del centó, una mena de poema compost amb finalitat paròdica a partir d'hemistiquis de Virgili. Algun fragment ha estat qualificat d’obscè («El desflorament», en què es descriu amb tota claredat el coit) i, fins i tot, censurat a diverses traduccions. ${ }^{4}$

Ja a l'antiguitat tardana, Claudià va presentar amb refinada sensualitat la pèrdua de la virginitat com a pugna amoris a l'última peça dels quatre Fescennina Honorii et Mariae dedicats, amb tota la seva dimensió pública i política, a l'emperador Honori:

No dudes, joven esposo, en atacar de cerca,

por más que, fiera, trate de defenderse con sus uñas.

4 Aquest és el cas de la traducció del llatí al català de C. Riba i A. Navarro (1928: 51-52); també el de H. G. Evelyn White, la traductora de la col lecció Loeb, que va deixar els versos en llatí (Serrano Cueto 2013: 105). Recentment «El desflorament» ha estat publicat en català a cura de J. Velaza (2017: 379-380) dins d'una selecció d'autors i textos llatins. 
Anna Garcia Busquets. A primera sang: batalles nupcials en la Catalunya barroca.Els epitalamis al galant Alba de Francesc Fontanella

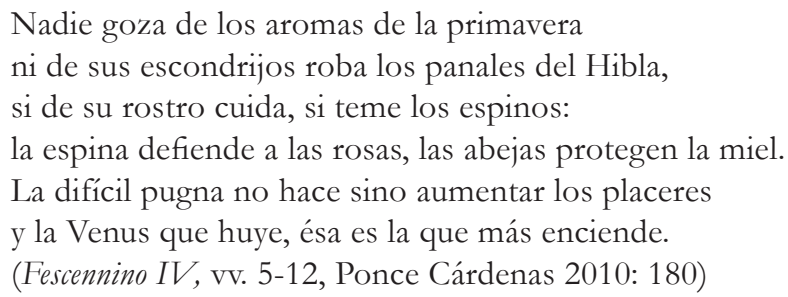

Advertim la referència a les taques sobre el llençol:

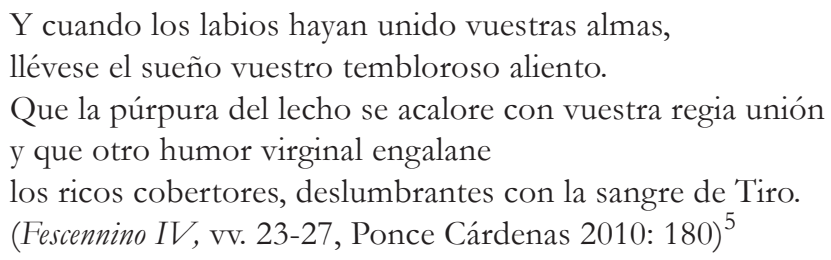

Després de Claudià es va introduir l'exaltació de la castedat i del model de matrimoni cristià, com a la composició de Paulí de Nola en honor a Julià, antecedent de l'epitalami medieval (Serrano Cueto 2013: 106). Segons Wilson, a l'alta edat mitjana pràcticament va desaparèixer el coneixement dels epitalamis no religiosos (1948: 35). Els cants nupcials van perdurar sota el simbolisme cristià, en què el nuvi equivalia a Jesucrist i la núvia a l'Església (Tanabe 2011: 63; Wilson 1948: 40-41). Tot i el renovat interès pels clàssics del s. XII, el tema va deixar de ser durant aquests segles la glorificació de l'amor laic (Wilson 1948: 49).

\section{2. Època moderna}

A partir del Quattrocento, l'Europa moderna va reprendre amb prodigalitat la tradició laudatòria d'erotisme estilitzat amb cants en llatí consagrats a la unió de les famílies il lustres. Es perseguia un objectiu propagandístic (dimensió social i política que tenia en Claudià l'antecedent), fer una demostració del poder i grandor de la nova aliança matrimonial als assistents. Hem d'entendre aquesta producció epitalàmica dins del marc de la poesia civil de circumstàncies, integrada pels poemes preliminars, epigrames dedicatoris, composicions per a naixements $i$ aniversaris, elegies funerals, panegírics... models que després es van repetir en llengua romanç sense venir directament dels clàssics, sinó de la fusió d'aquests amb els neollatins. Tot i que la tradició neollatina no va modificar el model clàssic en els seus elements estructurals fonamentals, sí que hi va afegir continguts nous:

El epitalamio en su versión neolatina se convierte en un género burgués, como poesía celebrativa de la familia (...) el epitalamio humanístico es también un poema sobre el sexo,

\footnotetext{
5 Sobre el Fescennino IV: «Según los cauces habituales de la militia amoris, el encuentro sexual entre los jóvenes se presenta ante los lectores bajo la maniera estilizada de la pintura de una lucha amorosa, donde la actitud viril (el arrojo encendido del emperador adolescente) contrasta con el rubor femenino y la resistencia pudorosa (la novia defenderá su virginidad con uñas y dientes). No parece exagerado afirmar que en esa minuciosa descripción del instante de la desfloración, de la pausa extática de dos almas fundidas en un beso, de los innumerables abrazos, del sueño delicioso que llega tras la postración física... puede entreverse uno de los pasajes más sensuales de la entera tradición nupcial antigua y moderna» (Ponce Cárdenas 2010: 180-181).
} 
Anna Garcia Busquets. A primera sang: batalles nupcials en la Catalunya barroca.Els epitalamis al galant Alba de Francesc Fontanella

\begin{abstract}
vehículo de escenas pornográficas. Este aspecto ya se encuentra en Ausonio, pero algunos epitalamios neolatinos lo desarrollan con mucha más gracia. Como dice Godelieve Tournoy: «La unión de los esposos, que en los poemas antiguos no es más que uno de los numerosos momentos de la ceremonia nupcial, se convierte en el tema central de los poemas de Pontano o Janus Secundus» (Alcina 1993: 12-13). ${ }^{6}$
\end{abstract}

En llengua italiana es va seguir aquesta línia d'epitalami sensual: Torquato Tasso (1544-1595) el va posar de moda a tot l'espai cortesà europeu. Altres autors foren Giambattista Marino (15691625), amb una col lecció de nuptialia en honor de llinatges nobles italians amb contingut obscè, o Marcello Giovanetti (1598-1631). A la secció de Rime nuziali de Giovanetti hi ha un sonet dedicat a les esposalles de Giacinto Centini i Girolama Malaspina, ${ }^{7}$ sustentat sobre el joc onomàstic de revelació i ocultament de la interpretatio nominis, molt emprat per Francesc Fontanella. L'espina del cognom de la núvia protegeix la rosa més preuada, que ferirà de passió el marit quan aquest, 'ja cenyit' (Giacinto = già cinto) amorosament al seu cos, intenti prendre la rosa (depredar rosa amorosa). Aquí la rosa vermella que sagna no és un símbol de bellesa o joventut, sinó una clara referència genital (cf. Ponce Cárdenas 2010: 192-194).

A mesura que avançava l'edat moderna, els textos epitalàmics destinats a personatges amb relleu dinàstic foren publicats acompanyats de belles imatges emblemàtiques i simbòliques a les portades (s. XVII) i a les pàgines interiors (s. XVIII). Garlandes i corones florals, cupidos i himeneus, roses, perles, coralls i magranes, cors inflamats... guarnien els escuts de les nissagues principals en la idiosincràtica confluència de les arts en el barroc. ${ }^{8}$

6 Sobre la cita, veg. Tournoy-Thoen (1980: 199). A Giovanni Pontano (1426-1503) i Janus Secundus (1511-1536) hi podríem afegir el neollatí Jean Salmon Macrin (1490-1557).

7 Per le nozze del signor Giacinto Centini con la signora Girolama Malaspina, formando due anagrammi ne’ loro nomi.

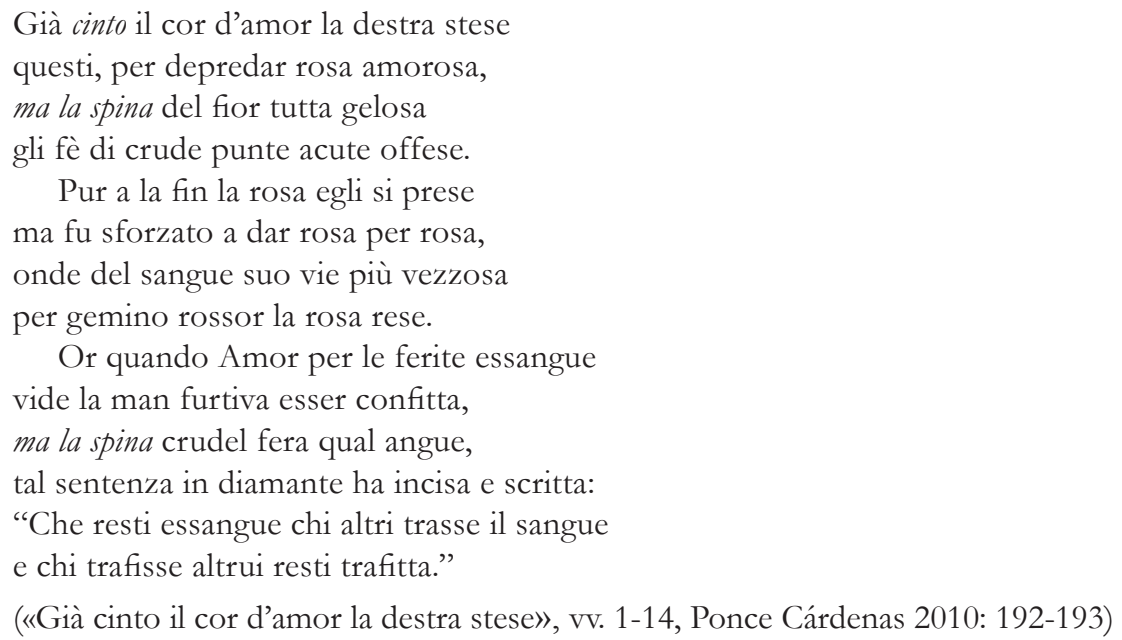

8 L'estudi de Rodríguez Moya (2011) aporta diversos exemples europeus de publicacions d'epitalamis amb emblemes.

SCRIPTA, Revista internacional de literatura i cultura medieval i moderna, núm. 10/desembre 2017/pp. 229-256

ISSN: 2340 - 4841 doi:10.7203/SCRIPTA.10.11081 
Anna Garcia Busquets. A primera sang: batalles nupcials en la Catalunya barroca.Els epitalamis al galant Alba de Francesc Fontanella

Tal i com va apuntar Alcina (1993: 13-14), en castellà no hi ha epitalamis documentats abans de 1530, tot i que els primers humanistes (Nebrija, Juan Partenio Tovar, Juan Petreyo...) van cultivar profusament el gènere en llatí. Al llarg del segle XVI, hi ha rastres del model epitalàmic a uns versos de l'Égloga II de Garcilaso (vv. 1401-1418) o a unes octaves burlesques d'Aldana («Octavas a lo pastoral»). Al barroc se'n van escriure molts gràcies a la difusió de poetes neollatins a través d'antologies i, a diferència del Renaixement, en llengua castellana. Van compondre epitalamis Luis de Góngora, Gabriel de Corral, García de Salcedo Coronel o Sebastián de Gadea. ${ }^{9}$ De Góngora, a part del conegut exemple del casament d'uns camperols a la Soledad primera, m'interessa ressaltar l'elogi $A l$ conde de Lemos, habiendo venido nueva de que era muerto en Nápoles, per les imatges emprades. Es tracta d'un panegíric funeral inacabat de l'any 1614 que consta de seixanta versos en què el poeta té temps d'explicar el naixement, educació i noces del personatge. Els següents versos de l'última estança corresponen al casament amb doña Catalina de la Cerda:

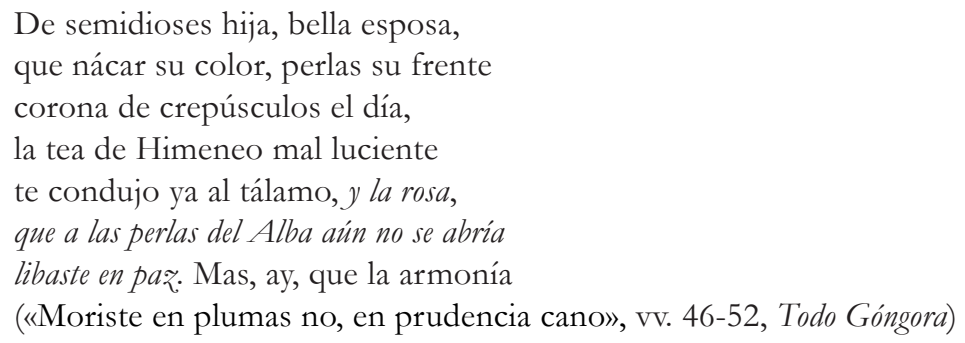

En aquesta cançó, Góngora va utilitzar el motiu de Claudià de la rosa i l'abella per referir-se al desflorament. La imatge també val per descriure un petó, ${ }^{10}$ com argumenta Jaume Coll en relació al poema del canonge tarragoní Antoni Massanés «Un canyelló li donava». Coll hi veu el correlat de l'epitalami sensual i situa la trobada entre Tirsi i Flora en un llit de noces. La sang (fruit del petó-mossegada) augmenta els elements eròtics de la composició (Coll 2016: 66).

\footnotetext{
9 Àmpliament estudiats per Ponce Cárdenas (2008). Sobre els epitalamis de caràcter cortesà en la literatura espanyola, veg. el complet estudi de M. Tanabe (2011: 75-81). Tanabe analitza el gènere epitalàmic a l'obra de Garcilaso, Sá de Miranda, Gaspar Gil Polo, Francisco de Aldana, Juan Rufo, Rey de Artieda, Lupercio Leonardo de Argensola i Lope de Vega, a més de Góngora.

10 Aquest tópos ha estat estudiat a fons per Ponce Cárdenas (2010: 197): «En el cambio resultante de las distintas reescrituras, se podría apreciar cómo, con el correr de los siglos, habría de producirse una inversión de los polos masculino y femenino, ya que en las literaturas vernáculas la abeja habrá de ser el varón que "robe” el néctar de la flon».
}

SCRIPTA, Revista internacional de literatura i cultura medieval i moderna, núm. 10/desembre 2017/pp. 229-256 ISSN: 2340 - 4841 doi:10.7203/SCRIPTA.10.11081 
Anna Garcia Busquets. A primera sang: batalles nupcials en la Catalunya barroca.Els epitalamis al galant Alba de Francesc Fontanella

\section{El cicle del galant Alba de Francesc Fontanella}

Francesc Fontanella va compondre sis epitalamis: la dècima «La flama junte ditxosa», el romanç amb un sonet inserit intitulat «On lo cristal lí Neptuno», ${ }^{11}$ i els quatre poemes dedicats al galant Alba, en els quals ens centrarem.

La seva primera editora, Maria-Mercè Miró, l'any 1995 els descrivia com una «sèrie de quatre cançons gradualment eròtiques, dedicades a les bodes d'un galant dit Alva (...) a Holanda» (Miró 1995: I, 82). L'edició de la poesia completa de Fontanella que va dur a terme Miró, sense anotació, presentava mancances importants posades de manifest per Pep Valsalobre (2015a: 86-87). ${ }^{12}$ A diferència de la de l'any 95, presentem una nova edició àmpliament anotada. ${ }^{13}$

Els epitalamis del galant Alba s’han transmès a través del manuscrit de la Biblioteca de Catalunya 27 (B1), el de la Reial Acadèmia de Bones Lletres de Barcelona 3-I-10 (L4) i el manuscrit núm. 68 de la Biblioteca Lambert Mata de Ripoll $(\mathrm{R})^{14}$ un nombre ben reduit de testimonis si tenim en compte que d'altres composicions de Fontanella n'arriben a tenir fins a catorze.

El conjunt dels quatre epitalamis (per aquest ordre: «Festiva, la matinada», «Entre lo cel i la terra», «Admira nostra campanya» $\mathrm{i}$ «Que bé comença lo dia») segueix la tradició del cant nupcial eròtic d'arrels clàssiques destinat a la noblesa i és una mostra única en la literatura catalana, que la col loca en el panorama europeu del «discurs del llit nupcial» conreat fins la Il lustració. Fontanella va fer servir un llenguatge elegant i metafòric per exposar gradualment les etapes que porten a l'acte carnal entès com a pugna amoris: els versos s'han d'entendre a través d'una doble lectura, en què la figura masculina és l'alba i la femenina, l'aurora. D’aquesta manera Fontanella va ampliar la identificació de Teòcrit 'núvia-aurora' amb una parella semàntica anàloga, 'nuvi-

11 A «La flama junte ditxosa» el tema central és la diferència d'edat dels contraents dels quals en desconeixem la identitat, tot i que es pot deduir que la núvia és una noia jove, educanda o novícia en un convent. «On lo cristal lí Neptuno», de caire burlesc, anava destinat a les noces de Joan Móra de Vilar, senyor de Corbera, amb Magdalena Xammar Ferrús al 1647. La parella formava part del cercle d'amistats de Francesc Fontanella. Podeu consultar l'edició crítica electrònica d'ambdós poemes que he dut a terme a Fontanella (2017).

12 Miró va transcriure d’ofici el ms. 268 de la Biblioteca Museu Episcopal de Vic i va remetre les variants respecte de les lliçons d'aquest testimoni a l'aparat. A més, l'edició de 1995 contenia errors en tots els nivells del procés ecdòtic i no considerava testimonis importants, tot i que en el cas concret del cicle del galant Alba sí els va tenir en compte.

13 Inclou els apartats de mètrica, localització als manuscrits, rúbriques, edicions anteriors, referències, aparat crític, notes a l'aparat, resum i notes explicatives.

14 De fet, el cicle sencer només el transmet R i en l'ordre de l'edició, al costat d'un conjunt força nombrós de poemes de transmissió única a R; B1 conté el primer i segon epitalami, i L4 el primer, tercer i quart. Els tres testimonis pertanyen a la mateixa branca principal de l'stemma. Segons Valsalobre (2015b: 172) B1 i L4 (a més del ms. 80 de la Biblioteca de Catalunya i del 3899 de la Biblioteca Nacional d'Espanya) transcriuen «els textos fontanellans de manera aleatòria, sense cap ordre aparent sovint desfent cicles i altres agrupacions que altres grups de manuscrits, com veurem, sí mantenen». L4 per exemple, que és un cançoner col lectiu amb obres majoritàriament de Garcia i Fontanella, insereix els tres epitalamis al mig de les giletes. Més dades sobre aquests testimonis a Rossich (2006) i Valsalobre (2015b). 
Anna Garcia Busquets. A primera sang: batalles nupcials en la Catalunya barroca.Els epitalamis al galant Alba de Francesc Fontanella

alba', resultat d'un joc onomàstic de revelació i ocultament semblant al que feia Giovanetti amb 'Già Cinto' i 'Malaspina'.

\section{«Festiva, la matinada»}

«Festiva, la matinada» és l'estadi inicial de la progressió. El poeta comença fent referència a la matinada d'un dia de festa. La matinada mostra el Sol, que s'ha dividit en dos per il luminar millor un Alba, personatge a qui va destinat el poema (vv. 1-4): «Festiva, la matinada / ostenta l'ardor gentil / que, per il lustrar un Alba, / en dos sols se dividí». Aquests dos sols són els ulls de la dama, tópos clàssic de la mirada com a desvetlladora del sentiment amorós tan habitual al neoplatonisme. Tot seguit, veiem com la celebració matrimonial acaba amb incerteses anteriors: L'alba serena (sense cap núvol o torbament) pot compensar feliçment les tristeses viscudes, que s'identifiquen amb la nit (vv. 5-8): «Oh, ben empleades penes / si recompensa, feliç, / l'alba serena d'un dia / tristeses de tantes nits!». Entenem que el nuvi ha patit llargament esperant que el seu amor fos correspost, com Estel la amb Violentil la (Estaci, Silves I 2, vv. 31-37) i tants altres.

A la tercera estrofa s'introdueix la pugna amoris a través de la imatge del combat militar (batalla), en què l'Alba és l'amant i el temor enemic es refereix a l'amada (vv. 9-12): «En les batalles de l'Alba / contra el temor enemic, / són les fontetes les caixes, / los ocellets, los clarins». Notem el paral lelisme estructural de fontetes / ocellets (termes bucòlics) i caixes / clarins (instruments musicals que acompanyaven els soldats a la guerra). Els símils escollits i els diminutius redimensionen a la baixa la ferocitat de la 'batalla' i estan en sintonia amb d'altres composicions de l'època, com la Letrilla lírica II de Góngora de 1609, en què la musicalitat dels elements naturals (el repicar rítmic de l'aigua i el brunzit de les abelles) s'expressa metafòricament. Advertim un lleu matís bèl lic en la salva -salutació mitjançant descàrrega d'armes de foc-i la presència del tópos dels dos sols, ulls de l'estimada (a continuació el refrany de la composició gongorina):

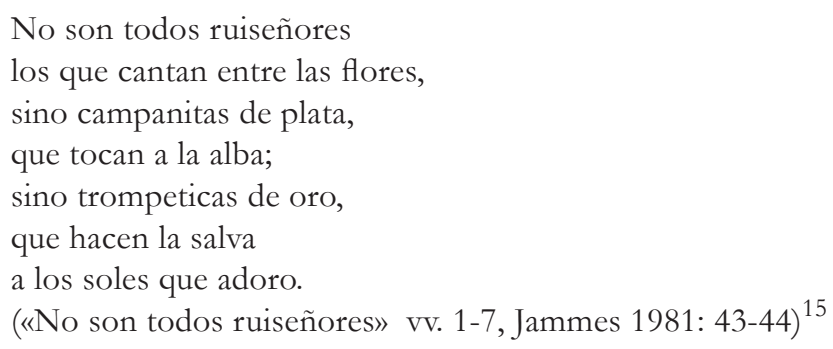

15 Sobre aquests versos va escriure Jorge Guillén: «Primero, trasposiciones dentro del orden físico: campanitas, pájaros, toda el Alba; trompeticas, pájaros, toda la Aurora -porque estos versos reúnen lo que las artes y las lenguas acostumbran a separar: La Aurora -el oro-, y el Alba -la plata-. ¿No significan, no son algo más esos repiques y toques de júbilo? "Que hacen la salva...” ¿Al Sol?... “...a los Soles que adoro”. Hasta este plural ocurría una alborada. Otro sol sale: ¿la Amada?, ¿los dos soles son los ojos de Ella? -“que adoro”. Falta el yo de ese "adoro”: el Amante. Quedan así, oblicuamente insinuados en la generalidad de la hora, los protagonistas del Amor» (Guillén 2002: 121-122). 
Anna Garcia Busquets. A primera sang: batalles nupcials en la Catalunya barroca.Els epitalamis al galant Alba de Francesc Fontanella

Si tornem a l'epitalami de Fontanella, veurem com arriba el moment del petó que simbòlicament representa la unió de les ànimes (vv. 13-16): «Què molt si prevé l'aurora, / ab esplendor cristal lí, / bella corona de perles / en dos encesos robins!». S’identifica la noia amb l'aurora, tal com marca la tradició; ${ }^{16}$ bella corona de perles són les dents i dos encesos robins, els llavis. ${ }^{17}$

Quant al refrany de «Festiva, la matinada» (vv. 17-21), «Mes ai de mi! / Ai, dilatada esperança! / Ai, apressurat desig! / Mes ai!, tinguen fi les penes / d'una amor que no té fi», notem l'oposició entre dilatada esperança (tot el temps esperat) i apressurat desig (el moment de la propera culminació) i la paronomàsia $f i / f i$, en què han d'acabar les penes d'un amor etern. ${ }^{18}$

\title{
«Entre lo Cel i la Terra»
}

El segon epitalami dedicat al galant Alba presenta el combat entre els dos Amors antagònics: el celestial i el terrenal o, en termes platònics, l'eros ouranios i l'eros pandemos. Segons Plató, ${ }^{19}$ el primer és

16 Ja hem vist en apartats anteriors com Teòcrit (Epitalami d'Hèlena i Menelau) descrivia Hèlena-Aurora com «la de la pell rosada». Els Idil lis van tenir gran difusió a tot Europa a l'edat moderna a través de diverses traduccions al llatí. Petrarca va fer ús del motiu al Canzoniere: «Quand'io veggio dal ciel scender l'aurora / co la fronte di rose et co' crin’ d'oro» (CCXCI, vv. 1-2), o Quevedo, al sonet amb rúbrica: Habiendo llamado a su zagala Aurora, pide a la del cielo que se detenga para ver en ella el retrato de su misma zagala.

17 Al bes entre Acis i Galatea del Polifemo, Góngora usa el terme 'robins' en un sentit semblant, tot i que en aquest cas referit a coloms: «No a las palomas concedió Cupido / juntar de sus dos picos los rubíes, / cuando al clavel el joven atrevido / las dos hojas le chupa carmesíes». Segons Coll (2016: 65) el petó en l'imaginari de Góngora porta al tàlem i queda clar tres versos més enllà, «llueven sobre el que Amor quiere que sea / tálamo de Acis ya y de Galatea» (Fábula de Polifemo y Galatea vv. 329-332 i 335-336, Parker 1984: 148), com a l'epitalami de Fontanella (apressurat desig, v. 19). Fontanella va emprar els termes 'perles' i 'robins' en el mateix sentit a d'altres poemes:

\author{
Què direm de l'amable boqueta, \\ on totes les gràcies tenen son jardí, \\ que l'aurora corona de perles \\ de perles que l'alba matisa ab robins? \\ («Amaranta, la nimfa més bella» vv. 13-16) \\ I a bé que l'alba i lo Sol \\ robins i perles engendren \\ no venceran de ta boca \\ ni los robins ni les perles. \\ («Reverencia’t ja l’aurora» vv. 5-8)
}

18 No s'ha de descartar la possibilitat que aquests poemes es cantessin. Tot apunta que el nombre de composicions fontanellanes escrites per a ser cantades amb acompanyament musical és més gran del que s'havia considerat fins ara, i que va més enllà d'aquelles en què a la rúbrica s'especifica clarament la tonada a seguir.

19 Sobre els dos tipus d'amor a Fedre, cf. Serés (1996: 20).

SCRIPTA, Revista internacional de literatura i cultura medieval i moderna, núm. 10/desembre 2017/pp. 229-256 ISSN: 2340 - 4841 doi:10.7203/SCRIPTA.10.11081 
Anna Garcia Busquets. A primera sang: batalles nupcials en la Catalunya barroca.Els epitalamis al galant Alba de Francesc Fontanella

capaç de superar la simple bellesa sensible de l'amat per abastar allò que amaga d'etern. Al s. XVII aquest antagonisme era força present, sobretot gràcies a humanistes italians com Marsilio Ficino i Baldassare Castiglione. Segons Ficino, l'experiència amorosa particular és només una condició prèvia per assolir l'amor ideal, una circumstància necessària per passar de la Venus vulgar a la Venus celeste (De amore, II, VII) i, d'acord amb Castiglione, és un requisit per a contemplar la bellesa universal (El cortesà, IV, 70) que precisa de la mort simbòlica de l'amor sensitiu (Serés 1996: 189-190).

En aquesta composició el fill de la Venus Urània o celeste (deessa de l'amor conjugal), venç l'Amor terrenal, fill de la Venus Pandèmona o vulgar (deessa de l'amor lliure). Fontanella, seguint la preceptiva epitalàmica, defensa la bondat de la institució del matrimoni. ${ }^{20}$

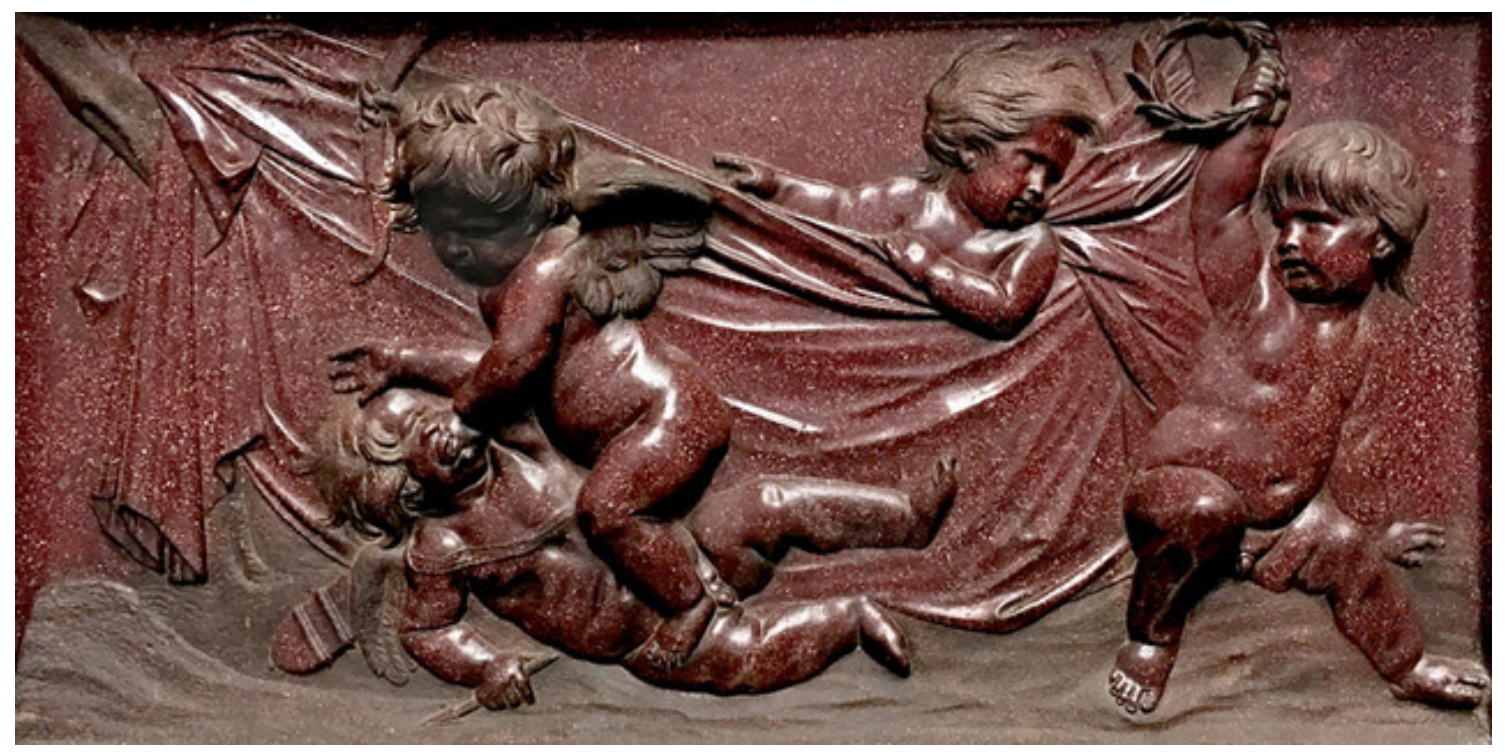

Fig. 1. L'Amor sagrat vencent l'Amor profà, Tomaso Fedele, 1630 (Museo del Prado, Madrid)

Aquest relleu en pòrfir (fig. 1) que ens serveix per il lustrar el segon epitalami fou un regal del cardenal Francesco Barberini a Felip IV, i és còpia d'un altra talla en marbre realitzada per François Duquesnoy (1597-1643) per decorar el jardí d'una de les vil les romanes de la família DoriaPamphili. El rètol del Museu del Prado refereix: «Escena con cuatro amorcillos. Dos de ellos,

20 La dualitat amorosa és, per descomptat, present a d'altres autors. Per posar-ne dos exemples, Giambattista Marino qualifica de lascivamente onesta (Rime amorose) la dona d'un dels seus poemes: lasciva per la carn, honesta per l'amor, que es vol verdader, pur (veg. Coll 2016: 68). Agustín de Salazar y Torres fa referència a l'Amor sagrat en oposició a la sensualitat de l'Amor profà: «No eres Amor vulgar, pues que las señas / desmientes que te fingen los deseos» («¿Dónde apresuras la dorada pluma?»vv. 27-28, Ponce Cárdenas 2008: 51), i «no aquel vendado ni ciego / vulgar Amor, hijo infame / de los ojos y el deseo» («iNo ignoraba yo, señor» vv. 18-20, Ponce Cárdenas 2008: 55).

SCRIPTA, Revista internacional de literatura i cultura medieval i moderna, núm. 10/desembre 2017/pp. 229-256 ISSN: 2340 - 4841 doi:10.7203/SCRIPTA.10.11081 
Anna Garcia Busquets. A primera sang: batalles nupcials en la Catalunya barroca.Els epitalamis al galant Alba de Francesc Fontanella

que representan al Amor Sagrado y al Amor Profano, están en plena lucha, y el primero abate al segundo».

El romanç comença amb el combat còsmic entre els dos Amors (vv. 1-4), en la línia moderna d'arquetips planetaris i poètica d'imatges celestes: «Entre lo Cel i la Terra, / en portentós desafiu, / Amor contra Amor pelea, / lo terrestre i lo diví». L'estrofa pot fer també esment, dins del context multireferencial del barroc, al final de la lluita entre el Cel (Urà) i la Terra (Gea) gràcies a Matrimoni. El tractadista Menandre de Laodicea recomanava que als epitalamis, just després del proemi, es tractés aquest tema:

\begin{abstract}
Tras los proemios sigan unas palabras sobre el dios del matrimonio a manera de tesis, que contengan la consideración general de que el matrimonio es un bien. Te remontarás muy atrás, diciendo que, inmediatamente después de la desaparición de Caos, Naturaleza creó a Matrimonio -y, si quieres, como dice Empédocles, también a Amor-; y, una vez nacido, ese dios une a Urano con Gea, a Crono con Rea, colaborando en ello con él Amor. A continuación has de decir que por medio del matrimonio se produjo la ordenación del Universo -el aire, los astros, el mar-; pues, tras poner fin ese dios al conflicto y unir en concordia y con ceremonia nupcial el cielo con la tierra, todo quedó definido y adquirió el estado que le es propio (Tractat II 401, García / Gutiérrez 1996: 197-198).
\end{abstract}

Seguidament (vv. 5-8), es desenvolupa l'Amor terrestre anunciat al v. 4: «Amor, amant de tenebres / perquè de la nit és fill, / ab los cometes per fletxes / augmenta horrors a la nit». Es descriu l'Amor terrestre com amant de tenebres, en referència a les visites que feia Cupido a la seva bella esposa Psique en la penombra per temor a Venus (cf. Apuleu, L'ase d'or, llibre V). El v. 6 és una al lusió a un mite que el feia fill de la Nit i d’Ėreb (cf. Ciceró, De natura deorum XVII, 44). Els cometes s'identifiquen per la seva forma amb les fletxes, atribut de Cupido (vv. 1-8). A la simbologia neoplatònica ficiniana (la influència directa o indirecta d'aquest humanista sobre els textos de Fontanella és evident, especialment a les giletes) la nit evoca ombres, tenebres, horror... en oposició al sol, font de llum i de vida. En aquesta línia s’ha d’interpretar el v. 8.

La tercera quarteta remet a l'Amor celestial o divi anunciat al v. 4 (vv. 9-12): «I l'altre, en càndido núvol, / per un iris cristal lí / porta la mort i la vida / als superbs i als humils». L’iris cristal lí és l'arc de Sant Martí, que serveix a Cupido per disparar a la humanitat sencera (als superbs $i$ als humils). Tal i com veiem a l'esbós d'Angelo Michele Colonna (fig. 2), Amor se solia representar sobre un núvol. ${ }^{21}$

21 El lligam amb l'arc Iris és present a d'altres poemes fontanellans: «No és tan clar, tan apacible / com l'Iris del cel d'Amor? /Amor l'estima per arc /que fletxa ditxosos cors» («Qui ha vist una blanca rosa?»vv. 9-12); o bé, «Si no de plata brunyida, / de marfil ters és son front, / iris que, en cel tan diví, / arc és de l’amor fogós» («Si del rigor lo poder» vv. 37-40). També a «Passà lo turment, Gileta, / i la turmenta passà: / és arc de l'Amor sens fletxa, / Iris de serena pau.» («Passà lo turment, Gileta» vv. 1-4). 
Anna Garcia Busquets. A primera sang: batalles nupcials en la Catalunya barroca.Els epitalamis al galant Alba de Francesc Fontanella

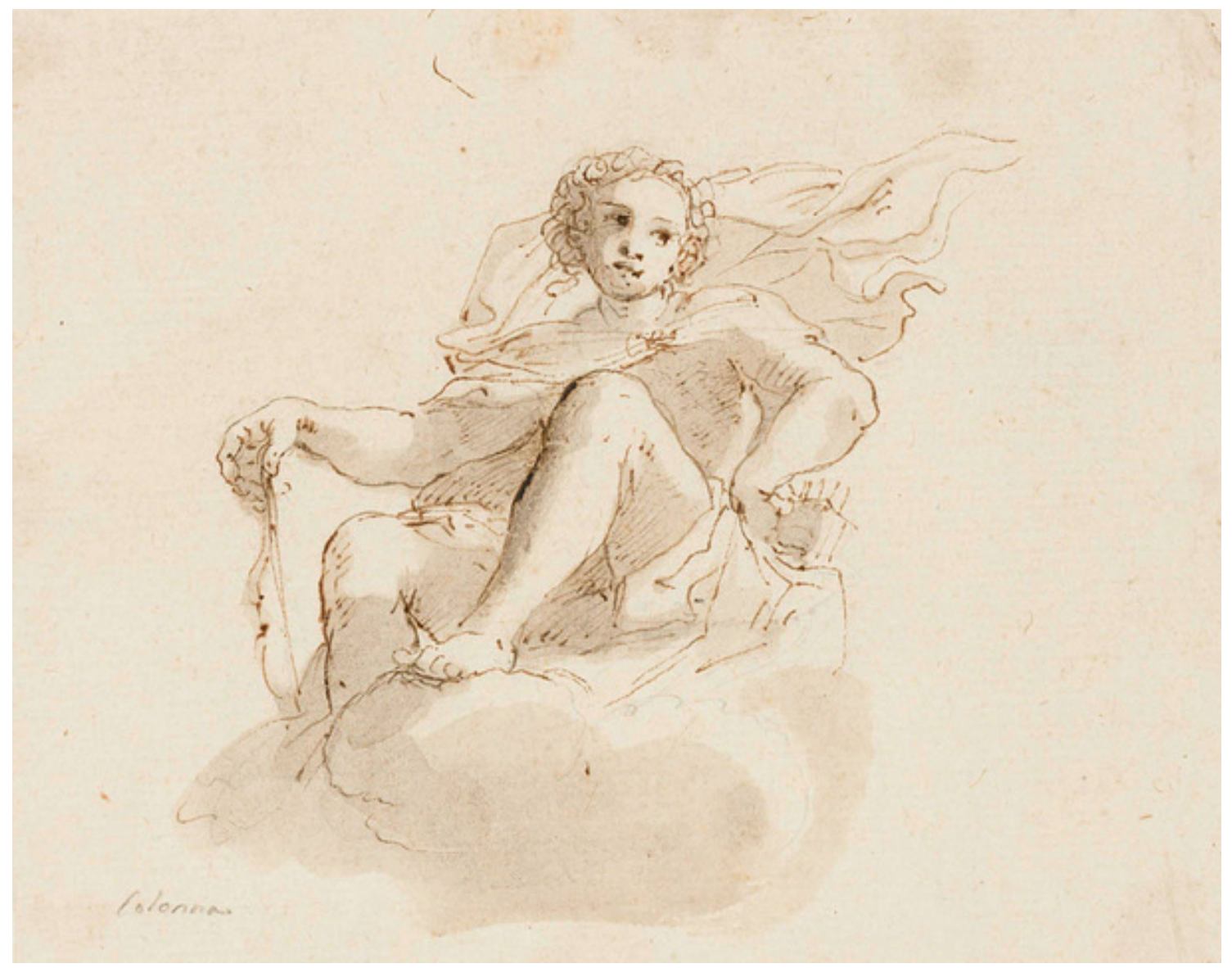

Fig. 2. Cupido assegut sobre núvols, Angelo Michele Colonna, s. XVII (Museo del Prado, Madrid)

Els nuvis són vencedors perquè ha guanyat l'amor etern, celestial, però també captius perquè l'estima els lliga un amb l'altre (vv. 13-16): «Amor de l'Amor triümfa / i els ditxosos esperits, / per tan divina victòria, / són vencedors i captius». I a continuació (vv. 17-20): «Batalla amable / combat feliç, / on Amor és vencedor / i altre Amor és fugitiu». L'amor fugitiu del darrer vers recorda El banquet de Plató, en què Pausànies feia referència a com s'escapa i fuig l'amor sensible:

Alhora, és pervers l'amant vulgar, aquell que estima més el cos que l'ànima, car a més ni tan sols és constant, ja que tampoc no és constant allò que estima: així que es marceix, en efecte, la flor del cos que estimava, «desapareix volant», després d'infringir moltes paraules i promeses (El banquet 183e, Leita 2010: 93). 
Anna Garcia Busquets. A primera sang: batalles nupcials en la Catalunya barroca.Els epitalamis al galant Alba de Francesc Fontanella

\section{«Admira nostra campanya»}

El tercer epitalami descriu la trobada sexual al tàlem com un estilitzat combat amorós. El terme campanya, terreny on un exèrcit feia la guerra, potencia l'ambient militar (vv. 1-4): «Admira nostra campanya / que en un gustós desafiu / a primera sang peleen / dos cors que l'amor uní». L'expressió a primera sang significa que el duel cessa quan un dels dos adversaris sagna; en aquest cas és una referència al desflorament de la núvia. L'expressió la trobem a d'altres textos de l'època com l'Epithalamio VII (1616) de Giambattista Marino, concretament a l'estança XXII: «Amor posciache strinse / l'uno a pugnar con l'altro, / (...) / quando vedesse al fin l'armi deporre / la bella coppia essangue / de la prima ferita il primo sangue». (Epithalamio VII, vv. 190-191 i 196-198, Ponce Cárdenas 2010: 195-196)

A continuació, el camp és el llit, oprimit per la pressió dels cossos (vv. 5-8): «Los combatents se despullen, / lo camp tremola oprimit, / i dos cors en un s'animen / ab los clarins dels sospirs». Seguidament s'insinua, a través del joc d'antònims, la vida conjugal que comença (vv. 9-12): «Entre suaus resistències / dura lo combat feliç, / que començant per un Alba / no ha d'acabar-lo una nit».

Segons les creences de l'Antiga Roma, les llàgrimes de Venus per Adonis moribund es transformaven en roses blanques. Mentre corria cap al seu estimat moribund, la deessa es punxava amb les espines $\mathrm{i}$ les tenyia de vermell (vv. 13-16): «No de l'espina de Venus / ixen les roses gentils: / la nova ignorada fletxa / dóna per flors los robins». En aquest cas les roses, gotes de sang provocades pel trencament de l'himen, ${ }^{22}$ no procedeixen de Venus. Com és sabut, la rosa és una imatge lligada al concepte de virginitat, molt difosa a tota la cultura occidental i, en particular, a la literatura epitalàmica des dels clàssics, especialment Claudià. La fletxa del v. 15, metàfora de l'òrgan masculí erèctil, és nova i ignorada perquè és la primera vegada que tenen relacions sexuals. Al v. 16 els robins són gotes de sang del desflorament, en un sentit idèntic a roses, i potencien la imatge recurrent de la noia com a vulnus ferus, fera ferida.

Tot seguit vénen els vv. 17-20: «quan sobre la neu d'holanda, / alegre, l'amor escriu / rendiments del vencedor / i victòries del rendit». Notem com la neu d'bolanda, que havia portat a Maria-Mercè Miró a confondre el galant Alba amb un cavaller holandès, és una referència als llençols blancs. L'holanda és una tela fina de lli amb què es confeccionen peces delicades i el país homònim al s. XVII n'era un dels principals fabricants. Al v. 18 l'amor escriu és una referència a les taques en el llençol (cf. l'bumor virginal que engalana los ricos cobertores de Claudià que hem vist anteriorment).

Els dos primers versos del refrany coincideixen amb «Entre lo Cel i la Terra» (vv. 21-24): «Batalla amable, / combat feliç, / on los dos són vencedors / quan los dos resten captius». Observem com, a més de carnal, la victòria és també espiritual.

22 Jean Salmon Macrin, en un to més bèl lic, va dir sobre el desflorament: «Ninguno se apodera de la corona de laurel / o excelso se muestra en triunfo sobre blancos corceles / si antes no regresa con el anhelado botín, / tras haber abatido al enemigo. / Encamínate hacia la palma de la victoria / a través de pasos amargos; y no cejes / hasta que pongas el trofeo en la cumbre, / sin importar cuántas rojizas oleadas de sangre manen» (Ponce Cárdenas 2010: 190). 
Anna Garcia Busquets. A primera sang: batalles nupcials en la Catalunya barroca.Els epitalamis al galant Alba de Francesc Fontanella

\section{«Que bé comença lo dia»}

El quart i últim epitalami dedicat al galant Alba descriu la parella realitzant l'acte sexual. La composició s'estructura sobre el contrast entre el blanc i el vermell, associació petrarquista: «et le rose vermiglie infra la neve» (sonet CXXXI del Canzoniere, vv. 1-2).

«Que bé comença lo dia: / mentres que l’alba feliç / entra adornada de perles, / cenyida de roses ix!» (vv. 1-4). Al volum Poesia eròtica i pornogräfica catalana del segle XVII tenim documentat l'ús de perles (en aquest context i en sentit figurat, rosada) com a 'gotes d'esperma'. L'expressió coincideix amb un poema eròtic anònim que diu: «iNo voleu que estiga trist / qui fa lo que no vol fer, / llançant perles al carrer, / guardades per la que call?» (Rossich 1985: 12, vv. 5-8). Com ja s'ha dit al poema anterior, les roses ${ }^{23} \mathrm{~s}^{\prime}$ han d'interpretar com les gotes de sang provinents del trencament de l'himen. Els verbs entra / ix són una clara al lusió al coit.

A més llegim que les roses (gotes de sang) són del febrer (vv. 5-8): «Roses del febrer hermoses, / ignorades a l'abril, / les que a la punta de l'alba / són filles d'un gessamí». Una possible explicació d'aquest 'febrer' seria que el casament, i la consegüent pèrdua de la virginitat, s'hagués celebrat durant aquest mes. Aquestes roses són desconegudes de la primavera (ignorades a l'abril) perquè no són flors. La punta de l'Alba és una nova referència viril, i el gessamí, la flor blanca i 'virginal' que representa la núvia.

Seguidament llegim (vv. 9-12), «llàgrimes d'un ull alegre / de coral i de marfil / que, entre dorades pestanyes, / ni veu ni vol ésser vist», versos en què podem entendre que l'ull alegre és una referència a l'orifici vaginal; les gotes de sang són llàgrimes d'aquest ull i les dorades pestanyes, el pèl púbic.

«És ullet tan admirable / que ab l'alba que el descobrí / si no té nina per veure, / per viure la pot tenir» (vv. 13-16). Fontanella expressa una visió plaent del sexe mitjançant la paronomàsia veureviure. «Robins i perles senyalen / lo dia sempre festiu, / quan les perles són de l'alba / i del sol són los robins» (vv. 17-20), en què la núvia resplendent és llum, aurora, sol... com havíem vist a «Festiva, la matinada».

El refrany recupera l'al lusió dels primers versos, dia (apacible)-alba feliç, i ens condueix vers un final amb intercanvi de colors i fluids (vv. 21-24): «Dia apacible, / alba feliç, / on són nevades les roses / i rosats los gessamins».

23 Sobre l'ús de les flors en la poesia castellana del Siglo de Oro, veg. la tesi doctoral de Javier de la Peña Álvarez (2010). La flor que més apareix és la rosa, seguida del clavell, i se la sol representar de color vermell com en aquest epitalami de Fontanella. L'estudi aporta exemples de set autors, entre els quals aquests primers versos d'un conegut sonet de Góngora de 1582 en què es descriuen les llàgrimes de l'estimada sobre el joc de blanc i vermell: «Cual parece al romper de la mañana / aljófar blanco sobre frescas rosas, / o cual por manos hecha, artificiosas, / bordadura de perlas sobre grana, / tales de mi pastora soberana / parecían las lágrimas hermosas, / sobre las dos mejillas milagrosas, / de quien mezcladas leche y sangre mana.» («Cual parece al romper de la mañana» vv. 1-8, Ciplijauskaite 1969: 116) 
Anna Garcia Busquets. A primera sang: batalles nupcials en la Catalunya barroca.Els epitalamis al galant Alba de Francesc Fontanella

\section{Sobre la identitat dels protagonistes}

En estudis anteriors s'ha intentat desvelar la identitat de l'enigmàtic galant Alba sense gaire èxit. ${ }^{24}$ En aquest estudi es planteja la hipòtesi que es tracti de Francesc de Sabastida i Ardena (1628-1655), que es casà amb Maria de Cartellà i d'Erill (1634-1674) el 16 de febrer de 1649 al castell de Falgons, poble del terme de Sant Miquel de Campmajor, al Pla de l'Estany (Lazerme 1975-1977: I, 81).

En primer lloc, la proposta se sosté en el fet que els nuvis pertanyien a la noblesa, en la línia de poema de circumstàncies que canta la unió de famílies il lustres tan típic a l'època moderna, com hem vist. Maria de Cartellà era la filla única i hereva de Galceran de Cartellà i d'Orís, baró de Granollers de Rocacorba i de Falgons, i de Francesca d'Erill i de Cardona, de la baronia lleidatana de l'Albi (jurisdicció que ocupa els actuals municipis de l'Albi i Cervià de Les Garrigues). La primera notícia del castell i la vila de l'Albi que es coneix és un conveni de 1166 entre Guillem de Cervera i Guillem de Timor a beneplàcit d'Alfons el Cast per organitzar el repoblament del territori (Lladonosa 1986: 50-51). La baronia de l'Albi estigué successivament en mans dels llinatges Timor, Albi, Mur (el baró Acard IV de Mur i Alemany de Cervelló fou capità general de Sardenya), Perellós (pel casament de Violant-Lluïsa de Mur amb Ponç de Perellós) i Cardona-Anglesola (per l'enllaç d'Elfa de Perellós amb Hug III de Cardona-Anglesola i de Centelles, baró de Bellpuig). Al s. XVI els seus successors foren els Erill i, a partir del matrimoni que ens ocupa, els Cartellà i els Sabastida.

El nuvi, Francesc de Sabastida i Ardena, era fill de Joan d'Ardena i d'Ortafà i de Lluïsa Sabastida i Bret, que amb el seu casament al 1610 van unificar el domini de la baronia de Darnius. Francesc, segongènit $i$ hereu de tota la renda, béns i drets de la casa Sabastida, va haver de canviar l'ordre dels cognoms (per tal de conservar el Sabastida) i prendre'n les armes. ${ }^{25}$ Els Sabastida posseïen una magnífica torre al barri barceloní d'Horta (derruïda durant la dècada dels 80 del s. XX) i els membres de la família eren enterrats a Santa Maria del Mar, en un espai reservat a la capella de Sant Francesc i Santa Clara. ${ }^{26}$ Com a conseqüència d'aquest emparentament entre Francesc i Maria, el llinatge adoptà el cognom de Cartellà de Sabastida, amb el que han estat més coneguts en coincidir amb la màxima esplendor i incidència social dels barons de l'Albi. El seu fill, batejat a Falgons l'1 de maig de 1651, Josep Galceran Cartellà de Sabastida, va ser ambaixador del Consell de Cent barceloní a la cort de Madrid (1693) i virrei de Mallorca (1698-1701).

24 S’ha comentat en pàgines anteriors com per Maria-Mercè Miró es tractava d’un cavaller holandès, supòsit basat en una mala interpretació del v. 17 de l'epitalami «Admira nostra campanya».

25 Així s'exigeix al testament (peça III) de la seva mare Lluïsa del 6 de juliol de 1639 davant el notari Antoni Joan Fitó de Barcelona, recollit a Alegacion jurídica por don Joseph de Çabastida de Ardena, Darnius y Cartellá, Baron del Albí en el pleyto que contra él siguen los ilustres Marqueses de Villel, Condes de Darnius, en la Real Audiencia sobre vindicacion de los bienes de Çabastida visto en 1801, Barcelona, Francisco Suriá y Burgada imp., 1801 (Fullet Bonsoms núm. 12.007, Biblioteca de Catalunya).

26 Francesc deixa per escrit la seva voluntat de ser-hi enterrat al testament, el 22 de gener de 1652, davant Roc Franch, notari a Girona (f. 59v et sq., not. 7, Arxiu Històric de Girona). Francesc va morir el 18 de setembre de 1655 i Maria de Cartellà es va tornar a casar amb Josep d'Armengol i Serra, senyor de Calabuig l'any 1668.

SCRIPTA, Revista internacional de literatura i cultura medieval i moderna, núm. 10/desembre 2017/pp. 229-256 ISSN: 2340 - 4841 doi:10.7203/SCRIPTA.10.11081 
Anna Garcia Busquets. A primera sang: batalles nupcials en la Catalunya barroca.Els epitalamis al galant Alba de Francesc Fontanella

En segon lloc, es pot establir que el galant Alba fou Francesc de Sabastida i Ardena perquè les famílies Fontanella i Ardena estaven íntimament relacionades. En els epitalamis dedicats a bodes autèntiques ( $\mathrm{i}$ no a personatges mítics), atès que eren poemes compostos per a una ocasió molt especial, hi havia d'haver una necessària relació de proximitat entre el poeta i els destinataris que podia anar més enllà del model cortesà europeu basat en relacions de mecenatge. Giovanni Pontano, per exemple, va compondre epitalamis amb motiu del seu propi casament amb Adriana Sassone el 1461, i també per a les bodes de les seves filles Aurèlia i Eugènia anys més tard, composicions incloses al poemari De amore coniugale. I l'humanista i arquebisbe de Tarragona, Antoni Agustí, va escriure l'any 1540 un carmen nuptiale per al casament de la seva germana Isabel amb el duc de Cardona (Serrano Cueto 2003: 162, 164).

Els Ardena militaven políticament en el partit francès com els Fontanella, i en la mateixa facció, enfrontada a la que dominava Josep de Margarit (Valsalobre 2008: 91). Josep d'Ardena (el primogènit) fou general en cap de la cavalleria catalana, i pertanyia a la mateixa generació que Josep Fontanella, germà gran del poeta i regent la Cancelleria, amb el qual se'l vincula documentalment en gran nombre d'esdeveniments. Va obtenir del rei de França el títol i els drets de compte d'Illa al Rosselló confiscats a Guillem Ramon de Montcada, marquès d'Aitona. Els seus pares (branques Ardena i Bret) tenien antigues propietats al Rosselló (a les viles d'Illa, Millars i Nefiac de la vall del riu Tet, així com a Perpinyà), ${ }^{27}$ com els Fontanella (branca Garraver, mercaders de Perpinyà). Josep d'Ardena estava casat amb Lluïsa d'Aragó i d'Aybar (personatge amagat sota el criptònim fontanellà 'Lise'); la seva germana Hipòlita d'Aragó i d'Aybar fou baronessa de l'Albi pocs anys abans que Lluïsa de Cartellà. A l'arbre genealògic que té al castell de Montsonís l'actual baró de l'Albi, Carles de Montoliu, es llegeix la llegenda «Hipolita De Aragón i de Aybar († 1666) "La conspiradora" en la guerra dels Segadors».

Els que estiguin familiaritzats amb les trames polítiques de la Guerra dels Segadors, ja saben que sobre Josep Fontanella planejava una ombra de sospita des de la seva missió diplomàtica a Münster, i va caure temporalment en descrèdit dins del partit profrancès per presumpta connivència no demostrada en les conspiracions pro-Felip IV d'Hipòlita i l'abat de Sant Pere de Galligants, Gispert d'Amat, l'any 1645 (Testino-Zafiropoulos 2010: 282-283). A finals de la dècada dels 40, Hipòlita i el seu marit Ramon Desplà, que tenien tendències polítiques antagòniques, es van separar. En morir Ramon sense descendència i després d'un breu període en mans de Jaume d'Erill, la baronia de l'Albi va passar a Francesca d'Erill i de Cardona.

A més, reforça el lligam Fontanella-Ardena el fet que Francesc de Sabastida i Ardena fos mestre de camp d'un dels terços de Barcelona com Francesc Granollacs, autor del poema «A les llàgrimes de Fontano en la mort de Nise» (Rossich / Valsalobre 2006: 270). Ambdós formarien part d'un cercle

27 Així consta a l'acte de presa de possessió d’aquestes propietats rosselloneses per part de Josep d'Ardena i la seva esposa, Lluïsa d'Aragó, entre el 18 i 22 de desembre de 1645: Fons ANC1-989 / Llinatge Rocabruna, barons de l'Albi (989 UC 13 núm. 3).

SCRIPTA, Revista internacional de literatura i cultura medieval i moderna, núm. 10/desembre 2017/pp. 229-256 ISSN: 2340 - 4841 doi:10.7203/SCRIPTA.10.11081 
Anna Garcia Busquets. A primera sang: batalles nupcials en la Catalunya barroca.Els epitalamis al galant Alba de Francesc Fontanella

d'amics-militars de Francesc Fontanella; el poeta arribà a exercir de governador de l'artilleria de Barcelona durant el setge de 1651-1652. ${ }^{28}$

Cal afegir dins dels nexes Ardena-Fontanella que Estàsia d'Ardena, germana de Francesc i Josep, va esdevenir durant l'exili a Perpinyà la segona muller de Francesc Fontanella.

En tercer lloc, quan defensem que Francesc de Sabastida fou el galant Alba, entenem 'galant' en el sentit de 'el que galanteja', 'el galant de'. El joc onomàstic de revelació i ocultament propi de la interpretatio nominis Alba-Albi és molt típic de Francesc Fontanella, que juga amb el cognom del destinatari com havíem vist que ho feia Giovanetti amb 'Malaspina'. Aquesta lògica deformativa la trobem a moltes composicions. Per exemple, a l'epitalami «On lo cristal lí Neptuno» (v. 55), Fontanella es refereix a don Pedro Soler com 'l'abat Peretti', un cardenal italià contemporani. Pere Soler de Peguera (†1659) fou un noble del braç militar emparentat amb el difunt Pau Claris i marit de Teresa Boixadors, que apareix sempre a la documentació com 'don Pedro'. ${ }^{29}$ Per citar algun exemple més, tenim el cavaller andant 'Francisco d'Alemanya' (Francesc Alemany) o el lleial escuder de Fontano, 'Manílio Guidèmio' (Manel Guiamet), de les cartes literàries del cicle de Belinda. ${ }^{30}$

Per acabar, el quart punt en què ens basem per concloure que el galant Alba fou Francesc de Sabastida ens ve del text mateix: Francesc i Maria es casaren el 16 de febrer de 1649, i si recordem el v. 5 de «Que bé comença lo dia», les roses del desflorament són del febrer: «Roses del febrer hermoses, / ignorades a l'abril, / les que a la punta de l'alba / són filles d'un gessamí».

28 Nomenament de l'11 de juliol de 1651. AHCB1-002/CCAM, 11/1B.III-5, Deliberacions de guerra, f. 46.

29 Tant al Manual de Novells Ardits, vol. XIV i XV, com als Dietaris de la Generalitat de Catalunya, vol. V i VI.

30 Sobre aquestes cartes, veg. l'acurat estudi de M. Sogues (2014). El mateix Sogues (2017) ha estudiat també la influencia de la tradició clàssica en els criptònim femenins a les cartes de Fontanella.

SCRIPTA, Revista internacional de literatura i cultura medieval i moderna, núm. 10/desembre 2017/pp. 229-256 ISSN: 2340 - 4841 doi:10.7203/SCRIPTA.10.11081 
Anna Garcia Busquets. A primera sang: batalles nupcials en la Catalunya barroca.Els epitalamis al galant Alba de Francesc Fontanella

Annex. El cicle del galant Alba. Edició crítica

«Festiva, la matinada»

Lletra per un galant anomenat Alba

Festiva, la matinada

ostenta l'ardor gentil

que, per il lustrar un Alba,

4

en dos sols se dividí.

Oh, ben empleades penes

si recompensa, feliç,

l'alba serena d'un dia

8

tristeses de tantes nits!

En les batalles de l'Alba

contra el temor enemic,

són les fontetes les caixes,

12

los ocellets, los clarins.

Què molt si prevé l'aurora, ab esplendor cristal lí, bella corona de perles

16 en dos encesos robins!

Mes ai de mi!

Ai, dilatada esperança!

Ai, apressurat desig!

20 Mes ai!, tinguen fi les penes

d'un amor que no té fi. ${ }^{31}$

Romanç + tetrasíl lab (v. 17).

B1 f. 44v-45; L4 pp. 266-267; R pp. 422-423.

\footnotetext{
31 Els versos s'han regularitzat ortogràficament d'acord amb els criteris d'edició exposats per A. Rossich a Poesia catalana del barroc. Antologia (Rossich 2006: 25-36) amb l'objectiu d'oferir al lector un text clar. Les rúbriques en cursiva corresponen a les del ms. R. Aquest testimoni és considerat el més important de tots els manuscrits fontanellans perquè transmet el nombre més gran de composicions, és l'únic que incorpora un pròleg d'autor, i és probable que sigui una còpia d'una col lecció poètica preparada pel mateix Fontanella en els darrers anys de la seva vida (Rossich / Miralles 2014: 90). L'edició del cicle del galant Alba que he dut a terme figura a l'Obra poètica completa de Francesc Fontanella, edició crítica electrònica allotjada a http://www.nise.cat (Valsalobre /Sogues 2017), com a part de la tesi doctoral en curs «La poesia civil de Francesc Fontanella (1622-1682/3)».
}

SCRIPTA, Revista internacional de literatura i cultura medieval i moderna, núm. 10/desembre 2017/pp. 229-256 ISSN: 2340 - 4841 doi:10.7203/SCRIPTA.10.11081 
Anna Garcia Busquets. A primera sang: batalles nupcials en la Catalunya barroca.Els epitalamis al galant Alba de Francesc Fontanella

B1: Lletra per un Galant dit Alva

L4: Per un Galan, ques deya Alba, en ocasio que estaba promes

R: Lletra per un Galant anomenat Alva

Edicions anteriors: Miró, M. M. (1995: II, 261); Vallverdú, J. (2015: 25).

Referències: Miralles, E. (2015: 211); Miró, M. M. (1995: I, 82); Vallverdú, J. (2015: 8-11 i 29-30).

5 empleades B1 R] empeadas L4 | 8 tristeses L4 R] tristesa B1

Basem l'edició en el ms. R.

2: al marge no amb una altra tinta L4.

5: corregit amb una altra tinta empleadas L4.

Primer dels quatre poemes nupcials en honor del galant Alba, possiblement Francesc de Sabastida i Ardena (1628-1655), que es casà amb Maria de Cartellà i d'Erill (1634-1674) el 16 de febrer de 1649 a Falgons (Sant Miquel de Campmajor, Pla de l'Estany). El castell de Falgons era propietat de la família de la núvia, filla única i hereva de Galceran de Cartellà i d’Oris, baró de Granollers de Rocacorba i de Falgons, i de Francesca d'Erill i de Cardona, baronessa d'Albi (Les Garrigues). Francesc d'Ardena, germà de Josep i d'Estàsia -que anys més tard es convertiria en la segona muller de Francesc Fontanella-, pertanyia al cercle íntim d'amistats de l'autor. Dins de la progressió gradual del cicle epitalàmic, «Festiva, la matinada» fa la funció de prolegomen.

1 festiva: de festa (per ser la data del casament).

2 ostenta: mostra; la matinada mostra l'ardor gentil ( $=\mathrm{Sol})$.

3 il lustrar il luminar; té el mateix sentit que a «Oh, què nova alegria / a l'orbe rara, / que lo Sol nos il lustra / antes que l'alba!» (refrany de «Hola, pastors de Betlem»). Aquí el Sol es divideix en dos per il luminar millor un Alba, destinatari del poema. Els dos sols són els ulls de la dama, tópos de la mirada com a desvetlladora del sentiment amorós.

5-8 L'alba serena d'un dia (subjecte) recompensa (=compensa, verb DCVB, 1), feliç (feliçment), les tristeses viscudes (que s'identifiquen amb la nit, antítesi). | serena: sense cap núvol (o torbament). La celebració matrimonial acaba amb les incerteses prèvies de la relació.

9-10 Al lusió a la lluita amorosa a través de la imatge del combat militar (batalla), en què l'alba és l'amant i el temor enemic, l'amada. Un model per a la literatura europea de la pugna amoris dins la tradició epitalàmica és Claudià (Fescennino IV), que exhorta el nuvi a batre's virilment i la núvia a abandonar la por i el pudor, i a no resistir-se al desig del nou marit (veg. Ponce Cárdenas 2010).

11-12 Paral lelisme estructural: fontetes / ocellets (termes bucòlics) i caixes / clarins (instruments musicals que acompanyaven els soldats a la guerra). | caixes: tambors militars; les gotes de les fonts repiquen com un tambor. El poeta dimensiona el combat en contrast irònic.

13-14 prevé: surt a camí, s'avança a una cosa. La claror cristal lina de l'alba (el nuvi) ve abans que l'aurora (la núvia). Aquests versos i els dos següents ens parlen de com el noi s'anticipa i besa la noia. 15-16 Referència a la boca de la núvia, en què bella corona de perles són les dents i dos encesos robins, els llavis. Cf. els vv. 13-16 del poema «Amaranta, la nimfa més bella»: «Què direm de l'amable boqueta, / on totes les gràcies tenen son jardí, / que l'aurora corona de perles / de perles que l'alba matisa 
Anna Garcia Busquets. A primera sang: batalles nupcials en la Catalunya barroca.Els epitalamis al galant Alba de Francesc Fontanella

ab robins?» o: «I a bé que l'alba i lo Sol / robins i perles engendren / no venceran de ta boca / ni los robins ni les perles.», (vv. 5-8 de «Reverencia't ja l'aurora»). També hi pot haver una al lusió a la corona de baró (en aquest cas, baronessa) que és d'or, perles i pedreria.

18-19 Oposició entre dilatada esperança (tot el temps que els amants han esperat) i apressurat desig (el moment de culminació).

20-21 fi / fi: que acabin les penes d'un amor que no acaba (etern).

\section{«Entre lo Cel i la Terra»}

Altre per lo mateix, ja nuvi

Entre lo Cel i la Terra,

en portentós desafiu, Amor contra Amor pelea,

4 lo terrestre i lo diví.

Amor, amant de tenebres perquè de la nit és fill, ab los cometes per fletxes augmenta horrors a la nit.

I l'altre, en càndido núvol, per un iris cristal lí porta la mort i la vida als superbs $i$ als humils.

Amor de l'Amor triümfa $i$ els ditxosos esperits, per tan divina victòria, 16 són vencedors i captius.

\section{Batalla amable,} combat felic,

on Amor és vencedor

$20 \quad i$ altre Amor és fugitiu.

Romanç + tetrasíl labs (vv. 17-18). 
Anna Garcia Busquets. A primera sang: batalles nupcials en la Catalunya barroca.Els epitalamis al galant Alba de Francesc Fontanella

B1 f. 45-45v; R p. 423.

B1: Altre al mateix ja nubi

R: Altre per lo mateix ja Nuvi

Edicions anteriors: Miró, M. M. (1995: II, 262); Vallverdú, J. (2015: 26).

Referències: Miralles, E. (2015: 211); Miró, E. (1995: I, 82); Vallverdú, J. (2015: 8-11, 29-30).

7 cometes B1] comites R | 19 és R] om. B1

Basem l'edició en el ms. R. Corregim l'error evident del v. 7.

Segon epitalami dedicat al galant Alba. Descriu la lluita entre els dos Amors antagònics: el celestial i el terrenal o, en termes platònics, l'eros ouranios i l'eros pandemos. Segons Plató (sobre les dues espècies d'amor a Fedre, veg. Serés 1996: 20), el primer transcendeix la simple bellesa sensible de l'ésser estimat per atènyer allò que amaga d'etern, mentre el segon es limita a l'amor sensible. En aquest poema l'Amor celeste venç l'Amor terrenal. Fontanella, seguint la preceptiva epitalàmica que inclou el bons auguris (els més freqüents eren a propòsit de la descendència i la prosperitat econòmica), desitja als nuvis un amor etern.

1 desafiu: desafiament. Notem que, hiperbòlicament, la pugna té una dimensió còsmica.

5-8 Desenvolupament de l'Amor terrestre apuntat a la primera estrofa. Cupido, amant de tenebres, sempre visitava la seva esposa Psique en la foscor de la nit, sense deixar-se veure (veg. Apuleu, L'ase d'or, llibre V). | cometes: cossos celestes del sistema solar acompanyats d'una llarga cua nebulosa; s'identifiquen per la seva forma amb un dels atributs de Cupido, les fletxes.

9-12 càndido: molt blanc. Sovint es representa Amor sobre un núvol. L'estrofa remet a l'Amor celestial o diví anunciat al v. 4. | iris cristal $v i$ arc de Sant Martí, que esdevé l'arc de Cupido amb el que dispara fletxes a tothom (als superbs $i$ als humils).

14 ditxosos esperits: les ànimes dels dos amants, dels nuvis.

16 vencedors $i$ captius: els amants són vencedors perquè ha guanyat l'amor etern, però també captius perquè l'estimació els lliga recíprocament.

17-18 És el mateix refrany dels vv. 21-22 de «Admira nostra campanya», tercer epitalami al galant Alba. Allà la batalla és entre els dos amants (la clàssica pugna amoris) en lloc dels Cupidos. 
Anna Garcia Busquets. A primera sang: batalles nupcials en la Catalunya barroca.Els epitalamis al galant Alba de Francesc Fontanella

III

\section{«Admira nostra campanya»}

Altra al mateix

Admira nostra campanya que en un gustós desafiu a primera sang peleen dos cors que l'amor uní.

Los combatents se despullen, lo camp tremola oprimit, i dos cors en un s'animen ab los clarins dels sospirs.

Entre suaus resistències dura lo combat feliç, que començant per un Alba no ha d'acabar-lo una nit.

No de l'espina de Venus ixen les roses gentils: la nova ignorada fletxa

16 dóna per flors los robins, quan sobre la neu d'holanda, alegre, l'amor escriu rendiments del vencedor

20 i victòries del rendit. Batalla amable, combat felic, on los dos són vencedors quan los dos resten captius.

Romanç + tetrasíl labs (vv. 21-22).

L4 f. 267; R p. 424.

L4: Al matex sent ya novi

R: Altra al mateix

Edicions anteriors: Miró, M. M. (1995: II, 263); Vallverdú, J. (2015: 27).

Referències: Miralles, E. (2015: 211); Miró, M. M. (1995: I, 82); Vallverdú, J. (2015: 8-11 i 29-30).

SCRIPTA, Revista internacional de literatura i cultura medieval i moderna, núm. 10/desembre 2017/pp. 229-256 ISSN: 2340 - 4841 doi:10.7203/SCRIPTA.10.11081 
Anna Garcia Busquets. A primera sang: batalles nupcials en la Catalunya barroca.Els epitalamis al galant Alba de Francesc Fontanella

9 suaus R] dolsas L4 | 14 les roses L4] los rosers R

Basem l'edició en el ms. R. Corregim l'error del v. 14.

6: al marge no amb una altra tinta L4.

14: per coherència amb els vv. 4 i 5 de «Que bé comença lo dia» proposem la lliçó les roses L4 en lloc de los rosers $\mathrm{R}$.

Tercer epitalami dedicat al galant Alba. Després del bes («Festiva, la matinada») i del triomf de l'amor etern («Entre lo Cel i la Terra»), ara és el torn de la trobada sexual al tàlem nupcial que, seguint la tradició, es descriu a través de metàfores com una estilitzada pugna amoris.

1 campanya: extensió de terreny descobert i fora les places fortificades, on els exèrcits es posaven en contacte amb l'enemic.

2 gustós desafiu, en la mateixa línia dels vv. 10 i 21-22.

3 a primera sang: el duel cessa quan un dels adversaris sagna; en aquest cas és una referència al desflorament de la núvia.

6 camp: metàfora de llit. El llit està oprimit per la pressió dels cossos.

9 Tòpic de l'oposició pudorosa femenina.

11-12 Joc d'antònims amb començant / acabar-lo i alba / nit que marca l'inici de les relacions conjugals. 13-14 Segons la mitologia, les llàgrimes de Venus es convertien en roses blanques durant la seva carrera cap a un Adonis agonitzant; mentre corria, la deessa es punxava amb les espines dels rosers $\mathrm{i}$ anava tenyint de vermell aquestes flors. En aquest cas, les roses (=les gotes de sang provocades pel trencament de l'himen, cf. vv. 4 i 5 de «Que bé comença lo dia») no procedeixen de Venus.

15 Metàfora de l'òrgan masculí erèctil (fletxa). És nova i ignorada perquè és la primera vegada que tenen relacions sexuals.

16 robins: gotes de sang del desflorament. Té un sentit idèntic a roses.

17 la neu d'holanda: llençols blancs. L'holanda és una tela fina de lli amb què es confeccionen peces delicades; pren el nom del país homònim, que al s. XVII n'era un dels principals fabricants i centre del comerç europeu.

18 l'amor escriu: es refereix a les taques en el llençol.

19-20 Referent bèl lic del triumphus: l'espòs (vencedor) acaba tan sotmès com l'esposa, extenuat per la laxitud post coitum; la noia (rendit), satisfeta sexualment, en surt igualment victoriosa.

21-22 Part del refrany coincident amb l'anterior composició, «Entre lo Cel i la Terra».

23-24 A més de carnal, la victòria és també espiritual. L'amor s'apodera d'ambdós i els lliga l'un amb l'altre; remet a la imatge dels cors entrellaçats dels vv. 4 i 7. 
Anna Garcia Busquets. A primera sang: batalles nupcials en la Catalunya barroca.Els epitalamis al galant Alba de Francesc Fontanella

IV

«Que bé comença lo dia»

4

Altra al mateix

Que bé comença lo dia:

mentres que l'alba feliç

entra adornada de perles,

cenyida de roses ix!

Roses del febrer hermoses, ignorades a l'abril, les que a la punta de l'alba són filles d'un gessamí;

llàgrimes d'un ull alegre de coral i de marfil que, entre dorades pestanyes,

12 ni veu ni vol ésser vist.

És ullet tan admirable que ab l'alba que el descobrí si no té nina per veure,

16 per viure la pot tenir.

Robins i perles senyalen lo dia sempre festiu, quan les perles són de l'alba

20 i del sol són los robins.

Dia apacible, alba felic, on són nevades les roses

$24 \quad i$ rosats los gessamins.

Romanç + tetrasíl labs (vv. 21-22).

L4 f. 267; R pp. 424-425.

L4: $\mathrm{Al}$ matex assumpto

R: Altra al mateix

Edicions anteriors: Miró, M. M. (1995: II, 264); Vallverdú, J. (2015: 28).

SCRIPTA, Revista internacional de literatura i cultura medieval i moderna, núm. 10/desembre 2017/pp. 229-256 ISSN: 2340 - 4841 doi:10.7203/SCRIPTA.10.11081 
Anna Garcia Busquets. A primera sang: batalles nupcials en la Catalunya barroca.Els epitalamis al galant Alba de Francesc Fontanella

Referències: Miralles, E. (2015: 211); Miró, M. M. (1995: I, 82); Vallverdú, J. (2015: 8-11 i 29-30).

6 al R] del L4

Basem l'edició en el ms. R.

6: Al marge no amb una altra tinta L4.

Quart i últim epitalami dedicat al galant Alba. Descriu la parella realitzant l'acte sexual, a través d'un joc de significats ric en metàfores florals i imatges d'elements preciosos del món mineral i animal. El poema s'estructura sobre el contrast entre el blanc i el vermell i incideix en el motiu literari del desflorament, molt present als poemes nupcials.

3-4 perles: les gotes d'esperma (cf. v. 19). | roses: les gotes de sang provinents del trencament de l'himen. | entra ... ix: al lusió al coit.

5-6 Les roses (=gotes de sang) són del febrer perquè el casament (i la pèrdua de la virginitat de la núvia) se celebrà aquest mes; la cerimònia fou el 16 de febrer de 1649. | ignorades a l'abril: L'abril, per definició, és la primavera, el moment d'esplendor floral. Aquestes roses són primerenques, desconegudes de la primavera (perquè no són realment flors).

7 Referència al gland. Recordem que el poeta juga tota l'estona amb l'equívoc entre Alba (nuvi) i alba (entrada del dia).

8 gessami: flor blanca i 'virginal' que representa la núvia.

9 ull alegre: orifici vaginal. Les gotes de sang són llàgrimes d'aquest ull.

$10 \mathrm{Al}$ lusió cromàtica a la part externa dels òrgans genitals femenins a través de materials valuosos d'origen animal: coral i marfil.

11 dorades pestanyes: pèl púbic.

15-16 veure-viure: paronomàsia que expressa una visió lúdica i plaent del sexe, cf. alegre v. 9. En tractar-se de l'obertura vulvar, és un ull que no té nina (=pupil la) per veure, però amb el nuvi (ab l'alba que el descobri) pot tenir nina (=penis) per viure (=gaudir).

17 Riquesa de les imatges minerals: robins i perles, que continuen el contrast entre el vermell i el blanc. Cf. coral i marfil, v. 10.

19 Cf. «te condujo ya al tálamo y la rosa, / que a las perlas del alba aun no se abría» (Góngora, Al conde de Lemos, habiendo venido nueva de que era muerto en Nápoles, vv. 50-51). Notem una lectura suplementària de perles (=les gotes d'esperma), que tant poden referir-se a l'esfera nacrada (cf. v. 17 al costat d'una altra joia: robins) com a la rosada, gotes d'aigua que es formen per condensació. 20 sol: la núvia, cf. vv. 1-4 de «Festiva, la matinada».

21-24 El refrany reprèn l'al lusió dels dos primers versos: dia (apacible)-alba feliç, i ens porta cap a un tancament enginyós amb l'intercanvi de colors i fluids. 
Anna Garcia Busquets. A primera sang: batalles nupcials en la Catalunya barroca.Els epitalamis al galant Alba de Francesc Fontanella

\section{Bibliografia}

Alcina, J. F. (1993) «Entre latín y romance: modelos neolatinos en la creación poética castellana de los Siglos de Oro», dins Maestre, J. M. / Pascual, J. (coords.), Humanismo y pervivencia del mundo clásico: actas del I Simposio sobre Humanismo y pervivencia del mundo clásico, (Alcañiz, 8 al 11 de mayo de 1990), I, Cadis, Universidad de Cádiz-Instituto de Estudios Turolenses, pp. 3-28, 2 vol.

Alsina, J. (trad.) (1963) Teòcrit, Idil lis, II, Barcelona, Fundació Bernat Metge, 2 vol.

Ciplijauskaite, B. (ed.) (1969) Luís de Góngora, Sonetos completos, Madrid, Castalia.

Coll Mariné, J. (2016) «Les confusions de les abelles: Un motiu poètic en Fontanella i Massanés», Els Marges, 108, pp. 51-74.

Colom, G. / Dolç, M. (trad.) (1957) Public Papini Estaci, Silves, I, Barcelona, Fundació Bernat Metge, 2 vol.

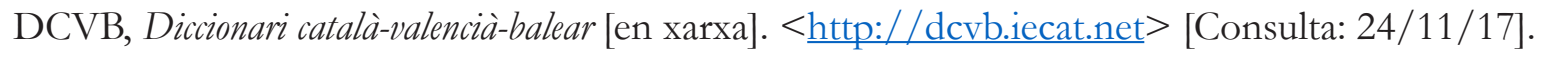

García, M. / Gutiérrez, J. (trad.) (1996) Menandro el Rétor, Dos tratados de retórica epidíctica, Madrid, Gredos.

Jammes, R. (ed.) (1981) Luís de Góngora, Letrillas, Madrid, Castalia.

Lazerme des Regnes, P. (1975-1977) Noblesa catalana. Cavallers y Burgesos honrats de Roselló y Cerdanya, La Roche-sur-Yon, Centrale de l'Ouest, 3 vol.

Leita, J. (trad.) (2010) Plató, El banquet. Fedre, Barcelona, Educaula.

Lladonosa Pujol, J. (1986) Història de la vila de l'Albi i la seva antiga baronia, Lleida, Diputació Provincial de Lleida.

Martínez Sariego, M. M. (2010) «El argumento del Carpe Diem en los epitalamios poéticos latinos», dins Luque, J. / Rincón, M. D. / Velázquez, I. (coords.), DULCES CAMENAE. Poética y Poesía Latinas, Granada, Universidad de Granada, pp. 261-270.

Miralles, E. (2015) «Algunes reflexions sobre la disposició textual d'un cançoner barroc (BLM, ms. 68). Per a una lectora: un llibre-ofrena i un testament literari», Zeitschrift für Katalanistik, 28, pp. 187-230.

Miró, M.M. (ed.) (1995) La poesia de Francesc Fontanella, Barcelona, Curial, 2 vol.

Montes Cala, J. G. (1996) «Teócrito, Idilio XVIII 26-28», Excerpta Philologica, 6, pp. 45-52.

Parker, A. (ed.) (1984) Luís de Góngora, Fábula de Polifemo y Galatea, Madrid, Cátedra.

Parramon, J. (trad.) (1999) Gai Lutaci Catul, Poesies completes, Barcelona, Edicions 62/Empúries.

Peña Álvarez, J. (2010) Flores en la poesía española del Renacimiento y Barroco, Madrid, Universidad Complutense de Madrid, Servicio de Publicaciones < http://eprints.ucm.es/10139> [Consulta: 10/10/17]. 
Anna Garcia Busquets. A primera sang: batalles nupcials en la Catalunya barroca.Els epitalamis al galant Alba de Francesc Fontanella

Piedra, A. / Bravo, J. (eds.) (2002) Jorge Guillén, Notas para una edición comentada de Góngora, Valladolid, Fundación Jorge Guillén / Universidad Castilla-La Mancha.

Ponce Cárdenas, J. (2008) «La variedad culta en Agustín de Salazar y Torres. Lectura de tres sonetos y dos epitalamios», AnMal, XXXI, 1, pp. 31-59.

(2010) «Eros nupcial: imágenes de la sensualidad en la poesía epitalámica europea», eHumanista, 15, pp. 176-208.

Riba, C. / Navarro, A. (trad.) (1928) Dècim Màxim Ausoni, Obres, II, Barcelona, Fundació Bernat Metge, 2 vol.

Rodríguez Moya, I. (2011) «Epitalamios e himeneos. Iconografía y literatura nupcial en las cortes del Barroco», IMAGO. Revista de Emblemática y Cultura Visual, 2, pp. 7-24.

Rossich, A. (ed.) (1985) Poesia eròtica i pornogräfica catalana del segle XVII, Barcelona, Quaderns Crema. (2006) «Notes sobre la transmissió textual de l'obra de Fontanella», dins Valsalobre, P. / Sansano, G. (eds.), Francesc Fontanella: una obra, una vida, un temps, Bellcaire d'Empordà, Edicions Vitel la, pp. 157-174.

(2006) «Criteris d'edició (Textos clàssics de l'edat moderna)», dins Rossich, A. / Valsalobre, P. (eds.) Poesia catalana del barroc. Antologia., Bellcaire d'Empordà, Edicions Vitel la, pp. 25-36.

Rossich, A. / Miralles, E. (2014) «Un pròleg desconegut de Francesc Fontanella», Els Marges, 102, pp. 90-102.

Rossich, A. / Valsalobre, P. (eds.) (2006) Poesia catalana del barroc. Antologia, Bellcaire d'Empordà, Edicions Vitel la.

Serés, G. (1996) La transformación de los amantes. Imágenes del amor de la Antigüedad al Siglo de Oro, Barcelona, Crítica.

Serrano Cueto, A. (2003) «La novia remisa y el novio ardiente en el epitalamio latino: una imagen que pervive en el Renacimiento», Cuadernos de Filología Clásica. Estudios Latinos, 23, pp. 53-70.

(2013) «El erotismo en la poesía nupcial latina de los siglos XV y XVI», Calamus Renascens, 14 , pp. 103-120.

Sogues, M. (2014) «L'erotisme a les Cartes a les Senyores dels Àngels i de Jerusalem, de Francesc Fontanella», Scripta. Revista Internacional de Literatura i Cultura Medieval i Moderna, 3, pp. 209-238 $<$ https://ojs.uv.es/index.php/scripta/article/view/3832>.

(2017) «Noms femenins de la tradició clàssica en la poesia de Francesc Fontanella», dins Miralles, E. / Malé, J. (eds.) Mites clàssics en la literatura catalana moderna i contemporania, II, Barcelona, Edicions de la Universitat de Barcelona, pp. 15-50.

Tanabe, M. (2011) «Tradición e innovación en el «epitalamio» de la primera Soledad», AnMal Electrónica, 30, pp. 59-89. 
Anna Garcia Busquets. A primera sang: batalles nupcials en la Catalunya barroca.Els epitalamis al galant Alba de Francesc Fontanella

Testino-Zafiropoulos, A. (2010) «La conspiration d'Hyppolite d'Aragon en Catalogne. Une courtisane et ses complices dans la tourmente franco-catalane», dins Pérez, B. (ed.), Ambassadeurs, Apprentis espions et Maîtres comploteurs. Les systèmes de renseignements en Espagne à l'époque moderne, París, PUPS, pp. 277-290.

Todo Góngora, Universitat Pompeu Fabra < https://www.upf.edu/todogongora/poesia/ canciones $/ 273 />$ [Consulta: 15/12/2017].

Tournoy-Thoen, G. (1980) «Les premiers éphithalames humanistes en France», Mélanges à la mémoire de Franco Simone, Ginebra, Slatkine, pp. 199-222.

Vallverdú, J. (2015) Noces de paper: El Cicle de casaments de Francesc Fontanella. Edició crítica, Universitat Oberta de Catalunya, treball de fi de grau dels estudis de Llengua i Literatura Catalanes [en xarxa] < http://openaccess.uoc.edu/webapps/o2/handle/10609/42762> [Consulta: 12/10/17].

Valsalobre, P. (2008) «Francesc Fontanella: una biografia excessiva», Revista de Catalunya, 239, pp. 71-98. $84-107$.

(2015a) «Per a una edició crítica de la poesia de Francesc Fontanella», Els Marges, 105, pp.

(2015b) «Sobre la transmissió manuscrita de l'obra poètica de Francesc Fontanella: els cançoners principals i l'ordenació dels textos», Zeitschrift für Katalanistik, 28, pp. 167-186.

Valsalobre, P. / Sogues, M. (coords.), Rossich, A., Miralles, E., Castaño, M., Garcia Busquets, A., Zaragoza, V., Figueras, N. (eds.) (2017) Francesc Fontanella, Obra poètica completa de Francesc Fontanella, edició crítica electrònica, Servei de Publicacions de la Universitat de Girona < $\underline{\text { http:// }}$ www.nise.cat/BibliotecaDigital/Autors/FrancescFontanella.aspx $>$.

Velaza, J. (ed.) (2017) Antologia de la literatura llatina, Barcelona, Universitat de Barcelona.

Wilson, E. F. (1948) «Pastoral and Epithalamium in Latin Literature», Speculum, 23, pp. 35-57. 